\title{
EFFECTS OF HOT-COLD OIL TREATMENT ON BIOLOGICAL RESISTANCE AND PHYSICAL PROPERTIES OF BRUTIA PINE SAPWOOD
}

\author{
Ahmet Ali Var ${ }^{1, \pm}$ \\ https://orcid.org/0000-0002-1531-5369 \\ Mesut Yalçin ${ }^{2}$ \\ https://orcid.org/0000-0002-5181-9484 \\ Ömer Ümit Yalçin ${ }^{3}$ \\ https://orcid.org/0000-0003-2241-3677 \\ Mehmet Demir \\ https://orcid.org/0000-0002-6486-5965
}

\begin{abstract}
This study investigated the physical properties of hot-cold oil-treated Brutia pine sapwood (Pinus brutia) and its biological resistance against wood-decay fungi. Weight percent gain, density, water absorption, and volumetric shrinking were chosen as the physical properties of the wood. White rot (Trametes versicolor) and brown rot (Neolentinus lepideus) were selected as the wood-decay fungi. Two different temperatures and two different time intervals were determined for the hot-cold oil treatment. Castor oil (Ricinus communis), flaxseed oil (Oleum linii), and a mixture of the two were used as the treatment oils (the medium of the hot-cold treatment). The results showed that the physical properties of the hot-cold oil-treated samples improved significantly compared to those of the control samples. In addition, after exposure to the decay fungi, the mass loss of the hot-cold flaxseed oil-treated samples decreased significantly more than in either the untreated samples or those treated with the other oils. There was a significant increase in the water repellent effectiveness and dimensional stability of the Brutia pine sapwood with all hot-cold oil treatments, but the hot-cold castor oil treatment appeared to have had no effect on decay resistance. A hot-cold oil treatment using flaxseed oil or a mixture including it could be a suitable method for improvement of the water repellent effectiveness, dimensional stability, and decay resistance of Brutia pine sapwood, as they both reduced the water uptake and the mass loss against the wood-decay fungi compared to the results of the control samples.
\end{abstract}

Keywords: Castor oil, decay resistance, flaxseed oil, hot-cold oil treatment, physical properties, pine wood.

${ }^{1}$ Isparta University of Applied Sciences, Faculty of Forestry, Department of Forest Biology and Wood Preservation Technology, Isparta, Turkey.

${ }^{2}$ Duzce University, Faculty of Forestry, Department of Forest Products Engineering, Duzce, Turkey.

${ }^{3}$ Isparta University of Applied Sciences, Faculty of Forestry, Department of Forest Products Chemistry and Technology, Isparta, Turkey. 


\section{INTRODUCTION}

Wood is an organic, renewable, and environmentally friendly natural material with beneficial properties. However, it is also associated with negative features such as dimensional changes, flammability, and biotic degradation. Many thermal process methods have been developed such as the Thermowood and Oil-heat treatment processes (Wang and Cooper 2005). These processes are among the techniques that improve some of the disadvantageous properties of wood material. It has been reported that thermal modification is a practical and eco-friendly process that reduces the hygroscopicity of wood, increases its dimensional stability and biotic resistance, and improves its color properties (Wang and Cooper 2005).

Bazyar (2012) reported that thermal modification reduced the swelling, shrinking, and equilibrium moisture content of wood material. In addition, it has been stated that heat treatment temperatures increase the resistance against biodegradation and moisture defects of wood, while only slightly changing the material properties (Hill 2006).

The oil heat treatment can serve as an alternative method for the modification of wood. Compared to normal heat treatment, this process can improve the disadvantageous properties of wood material. The oil heat treatment takes place in hot oil, while the normal heat treatment occurs under inert gases that do not react chemically under certain conditions. In oil heat treatment, the oils, applied at different temperatures and time duration, can be used as a good heat transfer medium and can also act as a potential carrier for other substances. This situation can further increase the effectiveness of the applied process (Tasdelen et al. 2019).

In recent years, there has been increasing use of plant oils in the thermal modification treatments of wood material. The oil heat treatments reduce the wood's moisture uptake, and also boost its performance against water absorption-related problems. Natural or raw herbal oils used as the heating medium in oil heat treatments include rapeseed oil, flaxseed oil, and sunflower oil (Rapp and Sailer 2000). It was reported that in wood treated with hot soy oil and then cooled within the same oil, the oil absorption increased depending on the increments of the cooling time, whereas the amount of water absorption and swelling decreased, thus improving the hydrophobicity and dimensional stability of the wood (Awoyemi et al. 2009).

Bak and Németh (2012) found that the equilibrium moisture content and the swelling rate decreased in wood material exposed to oil heat treatment with sunflower, flaxseed, and rapeseed oils. The anti-swelling effectiveness also increased, while the equilibrium moisture decreased because of the time and temperature increments of the treatment. It was stated that the equilibrium moisture content and volumetric shrinking had decreased in wood treated with hot flaxseed oil, and that the biological resistance against decay fungi had also improved. This increased resistance was attributed to the rising temperature.

Lee et al. (2018) stated that there is a common opinion that the minimum temperature for the oil heat treatment is $100{ }^{\circ} \mathrm{C}$ and, this varies depending on the tree species. It was reported that hot-cold oil heat treatment consisting of a hot oil treatment at $130{ }^{\circ} \mathrm{C}$ followed by a cold oil treatment at $80{ }^{\circ} \mathrm{C}$ provides $30 \%$ retention, and high-density linseed oil reduces water permeability compared to other oils (Lyon et al. 2007).

Tomak and Yildiz (2012) reported when wood samples are immersed in hot oil at $110^{\circ} \mathrm{C}-210{ }^{\circ} \mathrm{C}$ and then kept in cold oil at $10^{\circ} \mathrm{C}-90^{\circ} \mathrm{C}$, the oily preservative penetrates deeply into the wood material because of the pressure difference that is caused by the temperature change.

The research that uses the hot-cold dip method, solignum, neem leaf extract, and spent motor oil declared that the preservative penetration and absorption increased, and the weight loss decreased, and the decay resistance improved (Falemara et al. 2015).

Németh et al. (2009) subjected the samples of Poplar and Robinia wood to oil heat treatment with sunflower oil, linseed oil, and rapeseed oil. As a result, they stated that such oil heat treatments caused low strength values in material, and but increased its compression strength, and as the values of impact bending strength decreased, the material became more frangible.

It is indicated that when water-repellent oils penetrate deep into wood material, the material's effectiveness against water uptake-related problems can be increased. Such oils are commonly applied to wood material via the immersion, vacuum, or open tank hot-cold dipping methods. The hot-cold dipping method can provide 
uniform oil absorption throughout the wood material. This processing can be applied in the following two ways. 1) The wood material is held in the hot oil tank for a certain time and then removed, after which it is kept in cold oil of the same type in the other tank for additional time. 2) The wood material is kept in the hot oil for a certain period of time, and then is held there until the oil cools, after which it is finally removed from the oil. Thus, for both cases, a pressure difference (vacuum) can occur with the temperature change during the treatment. This vacuum can enable the treatment oil to better penetrate the wood material (Bozkurt et al. 1993).

Innovative strategic approaches form the basis of commercial and economic operations. In this sense, one of the strategic materials is the wood. Wood modification via hot-cold oil treatment may be an alternative strategic approach because the biological resistance and physical properties are directly related to the service life and all other technological properties of the wood. In addition to these features, a great many studies have been conducted investigating the effect of heat treatment on other properties of wood such as color changes and mechanical properties (Wang and Cooper 2005). However, no study to date has examined the effect of hot-cold oil treatment on these properties of wood.

Therefore, this study aimed to determine the changes in biological resistance and physical properties of sapwood samples of Brutia pine that had been subjected to hot-cold oil treatment with various plant oils. In this context, the study compared the biological resistance and physical properties of hot-cold oil-treated wood with those of untreated wood, evaluated the effects of the applied treatment on the abovementioned properties, and presented the significance level of these effects.

Turkey has important potential with regard to oil-producing plants and plants with oily seeds. Such wonderful multi-purpose plants constitute an important source of raw oil for many sectors, including the biodiesel, chemical, food, and paint industries (Onat et al. 2017). In addition, these plants meet a large part of the need for vegetable oils as well (Kolsarici et al. 2015). If organic oils produced from such renewable vegetable sources are also used in different industrial sectors such as the wood preservation and the wood modification industries, benefits can be realized in both domains and problems relating to the natural environment can be minimized. In this sense also, the hot-cold oil treatment applied using vegetable oils can make an important contribution.

Nowadays, due to the escalating use of chemicals that threaten human health and the natural environment, more restrictions related to these problems are being put in place. Therefore, treatment (modification) using vegetable oils can both improve the negative properties of the wood material and reduce environmental problems caused by toxic chemical-based oils. From this aspect, this study, with its environmentally friendly approach to wood preservation, can be considered as an important contribution to the literature.

\section{MATERIALS AND METHODS}

Brutia pine (Pinus brutia L.) sapwood samples, castor oil (Ricinus communis L.), flaxseed oil (Oleum linii), and mixed oil (castor oil $50 \%$ + flaxseed oil $50 \%$ ) were used in this study. These oils were utilized as the hot-cold treatment medium in the investigation of the decay resistance and the physical properties of the wood samples. The wood samples were subjected to hot-cold oil treatment according to the parameters in Table 1.

Table 1: Process parameters for hot-cold oil treated-Brutia pine sapwood.

\begin{tabular}{|c|c|c|c|}
\hline \multicolumn{2}{|c|}{ Hot oil treatment } & \multicolumn{2}{c|}{ Cold oil treatment } \\
\hline Temperature & Time & Temperature & Time \\
\hline $110^{\circ} \mathrm{C} \pm 2{ }^{\circ} \mathrm{C}$ & 6 hours & $23^{\circ} \mathrm{C} \pm 2{ }^{\circ} \mathrm{C}$ & 2 hours \\
\hline
\end{tabular}

\section{Wood samples}

The wood samples used for the tests were obtained from the sapwood section of three different pine logs. The logs were cut randomly from natural Brutia pine forests in the Isparta region of Turkey. Each pine tree was $63( \pm 1)$ years old. The wood samples were prepared in radial $(\mathrm{R}) \times \operatorname{tangential}(\mathrm{T}) \times$ longitudinal $(\mathrm{L})$ dimensions and contained no defects such as cracks, decay, or knots. The samples were conditioned until reaching dry air humidity (ISO 4471 1982), and then oven-dried at $103{ }^{\circ} \mathrm{C} \pm 2{ }^{\circ} \mathrm{C}$ to a constant weight and cooled to 
normal room temperature in a desiccator (ISO 13061-1 2014). At least five samples were used for each white rot and brown rot decay resistance test. At least ten samples were cut for each physical test (weight percent gain (WPG), density, water absorption (WA), and volumetric shrinking (VSH)). The wood samples were cut to the size of $30(\mathrm{R}) \times 30(\mathrm{~T}) \times 15(\mathrm{~L}) \mathrm{mm}^{3}$ for the WPG and WA tests and to the size of $20(\mathrm{R}) \times 20(\mathrm{~T}) \times 30(\mathrm{~L})$ $\mathrm{mm}^{3}$ for the decay resistance, density, and VSH tests. Prior to the hot-cold oil treatments, the wood samples had achieved approximate oven-dry (full dry) state because it has been reported that under such a condition, the oil transfer capacity within the samples is easier to achieve (Bazyar 2012).

\section{Treatment oils}

The properties of the treatment oils are presented here. Castor oil is an odorless (or has a very slight smell), pale yellow liquid, insoluble in water, and having a boiling point of $313{ }^{\circ} \mathrm{C}$ (Acar 2019), a density $\left(25^{\circ} \mathrm{C}\right)$ and viscosity $\left(40{ }^{\circ} \mathrm{C}\right.$ ) of $0,950 \mathrm{~g} / \mathrm{cm}^{3}-0,974 \mathrm{~g} / \mathrm{cm}^{3}$ and $240 \mathrm{~mm}^{2} / \mathrm{s}-300 \mathrm{~mm}^{2} / \mathrm{s}$, respectively (Scholz and Silva 2008). Flaxseed oil is the raw material used for varnish and oil-based paints and contains a great amount of unsaturated fatty acids and a significant amount of potassium, as well as magnesium, iron, copper, and zinc (Nicholas 1973). In water-repellent formulations, it can form hydrogen bonds and has a high molecular weight compared to water. It can create protective inner and outer surface layers against moisture (Schneider 1980) and is able to provide rapid and stable heat transfer within the wood structure. This oil also provides important heat treatment parameters including a suitable boiling point and a tendency for polymerization (Sailer and Rapp 2001).

\section{Hot-Cold oil treatment of wood samples}

The hot-cold oil treatment was achieved in accordance with the terms and conditions of the TS 345 (2012) standard. Two open-mouthed tanks were used to treat the wood samples with the oils. The tanks are specially designed laboratory-type containers made of stainless steel. One of the tanks (Tank 1) was for the hot oil treatment and the other (Tank 2) for the cold oil treatment. First, the wood samples were placed in Tank 1 followed by the raw oil. The raw oil was heated in Tank 1 until it reached the desired temperature. The hot oil treatment commenced when the oil temperature reached $110{ }^{\circ} \mathrm{C} \pm 2{ }^{\circ} \mathrm{C}$. After the samples had been kept within the hot oil for $6 \mathrm{~h}$, they were immediately removed from Tank 1 and then immersed in the cold oil (23 ${ }^{\circ} \mathrm{C} \pm 2{ }^{\circ} \mathrm{C}$ ) in Tank 2 and removed after 2 hours. Finally, after applying 0,1 atmospheric vacuum to remove the excess and residual oil on the samples, their gross dimensions and weights were measured. The samples were oven-dried at $60 \pm 2{ }^{\circ} \mathrm{C}$ to a stable weight and then cooled to normal room temperature in the desiccator and their net weights and dimensions were remeasured. Before testing was carried out, all these processes were repeated in the same way for each of the treatment oils. The amount of oil absorbed by the samples was determined by calculating WPG (Weight Percent Gain).

\section{Biological resistance tests}

The biological (decay) resistance of the treated and untreated control Brutia pine sapwood samples against Trametes versicolor (white rot) and Neolentinus lepideus (brown rot) was measured according to the TS 5563 EN 113 (1996) standard with minor modification in sample size. First of all a 3,7 \% malt extract agar medium was prepared for the test fungi. Later, all of the full-dry treated and untreated wood samples were incubated in petri dishes at $25{ }^{\circ} \mathrm{C}$ and $75 \% \mathrm{RH}$ for 12 weeks, after which the samples were taken from the incubator and then redried and reweighed. Before the decay resistance was evaluated, the mass loss values (\%) caused by fungal degradation were measured separately for each of the treated and untreated control samples.

\section{Physical properties tests}

The physical properties tested for the Brutia pine sapwood included the weight percent gain (WPG), density, water absorption (WA), and volumetric shrinking (VSH). These physical properties of the wood samples were recorded according to the following international laboratory standards: ASTM D1413-07e1 (2007) for WPG measurements, ISO 13061-2 (2014) for density measurements, and ISO 4858 (1982) for VSH measurements. The WA measurements were determined in accordance with Rowell and Banks 1985.

\section{Statistical analysis}

All measured data were statistically analyzed by one-way analysis of variance (ANOVA). The average values of the tested properties were compared using Duncan's Multiple Range Test (DMRT) to allocate the differences between the effects of the hot-cold oil treatments. 


\section{RESULTS AND DISCUSSION}

\section{Decay resistance}

Table 2 lists the results of the decay resistance test for the wood samples with and without the hot-cold oil treatment. Figure 1 shows the mass loss changes of the wood samples. The change values were calculated by comparison with those of the controls.

Table 2: Mass loss results of the control and treated Brutia pine sapwood samples against Trametes versicolor and Neolentinus lepideus.

\begin{tabular}{|c|c|c|}
\hline \multirow{2}{*}{ Treatments } & Trametes versicolor & Neolentinus lepideus \\
\cline { 2 - 3 } & Mean $(\%)^{*}$ & Mean $(\%)^{*}$ \\
\hline Control & $26,47 \pm 1,9 \mathrm{c}$ & $28,22 \pm 1,0 \mathrm{~g}$ \\
\hline Castor oil & $32,90 \pm 1,3 \mathrm{~d}$ & $32,04 \pm 2,1 \mathrm{~h}$ \\
\hline Flaxseed oil & $14,63 \pm 2,3 \mathrm{a}$ & $13,20 \pm 1,5 \mathrm{e}$ \\
\hline Mixed oil & $20,71 \pm 2,9 \mathrm{~b}$ & $16,28 \pm 1,8 \mathrm{f}$ \\
\hline
\end{tabular}

*Values with different letters displayed within the same column are significantly different at $95 \%$ confidence level $(p \leq 0,05)$.

The mass loss values of the test (treated) and untreated (control) samples exposed to both Trametes versicolor and Neolentinus lepideus were compared (Table 2). The mass loss after the hot-cold flaxseed oil treatment was 14,63 \% and 13,20\% for exposure to Trametes versicolor and Neolentinus lepideus, respectively. The mass loss for the samples with the mixed oil treatment as $20,71 \%$ for Trametes versicolor and 16,28 \% for Neolentinus lepideus. However, the mass loss values in the test samples were higher for the hot-cold castor oil treatment. This mass loss was observed to be 32,90\% for Trametes versicolor and 32,04 \% for Neolentinus lepideus. Table 2 revealed that, according to the ANOVA results, the hot-cold oil treatment exhibited a statistically significant effect on the decay resistance of the wood samples. The mass loss values for the control samples exposed to the degradative effects of Trametes versicolor and Neolentinus lepideus for 12 weeks were higher than those of the treated samples. The hot-cold oil treatment provided a significant increase in the decay resistance of the samples against both the white rot and the brown rot fungi. The best decay resistance results were observed in the wood samples hot-cold treated with flaxseed oil. Similar results were obtained with the hot-cold mixed oil process. However, the hot-cold castor oil reduced the decay resistance of the wood samples.

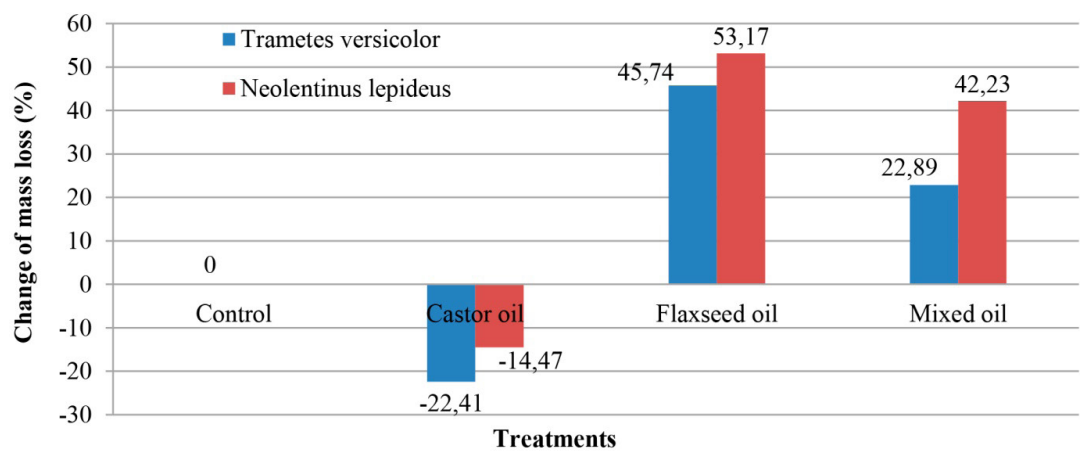

Figure 1: Mass loss differences of the control and treated wood against Trametes versicolor and Neolentinus lepideus. 
Bazyar (2012) found that the mass loss after exposure to Coriolus versicolor and Coniophora puteana for 16 weeks was lower for oil heat-treated-aspen wood compared to untreated wood. Welzbacher and Rapp (2002) also reported that oil heat treatment improved the decay resistance against Coriolus versicolor and Coniophora puteana for spruce and pine wood samples. The difference in decay resistance of the hot-cold oil treated-Brutia pine wood may due to the decrease of hydroxyl groups in the holocellulose and the changes within the chemical structure of the wood (Tjeerdsma et al. 2002). One study reported that there was a good correlation between the resistance increase in heat-treated wood and the hygroscopicity (Tjeerdsma et al. 2002). Another study stated that the important parameters for reducing the equilibrium moisture of heat-treated wood and increasing its biological resistance include the reduction of hydroxyl groups in the holocellulose, chemical changes, and lignin cross-linking (Nuoponen 2005).

\section{Physical properties}

The findings and discussion regarding testing of the physical properties of the hot-cold oil-treated Brutia pine sapwood samples and the untreated controls are presented separately below.

\section{Weight percent gain}

Table 3 gives the results of the weight percent gain (WPG) test for the hot-cold oil-treated wood samples. Figure 2 indicates the WPG changes for all the wood samples. The change rates were calculated according to the oven-dry weight before treatment.

Table 3: WPG results of the treated Brutia pine sapwood samples.

\begin{tabular}{|c|c|}
\hline Treatments & Mean (\%)* \\
\hline Control & - \\
\hline Castor oil & $40,84 \pm 11,3 \mathrm{a}$ \\
\hline Flaxseed oil & $75,72 \pm 11,4 \mathrm{~b}$ \\
\hline Mixed oil & $56,91 \pm 5,7 \mathrm{c}$ \\
\hline
\end{tabular}

*The difference between the values indicated by different letters within the same column is significant ( $p \leq 0,05 ; 95 \%)$.

The hot-cold oil treatment had a statistically significant effect on the WPG values of the wood samples. These effects differed significantly at the $95 \%$ confidence level. The measured WPG values of the samples ranged from about $41 \%$ to $76 \%$. The highest WPG value was measured after the flaxseed oil treatment, while the lowest was obtained after the castor oil treatment. A WPG value of about $57 \%$ was measured after the mixed oil treatment. Moreover, the mixed oil treatment significantly increased the WPG value of the wood samples compared to the castor oil treatment. For this mixed oil treatment, the WPG value was about $40 \%$ more than for the castor oil treatment, while it was about $33 \%$ less than for the flaxseed oil treatment. This reduction may have been due to the castor oil content within the mixed oil because in Table 3 , we observed a lower WPG value for the hot-cold castor oil treatment.

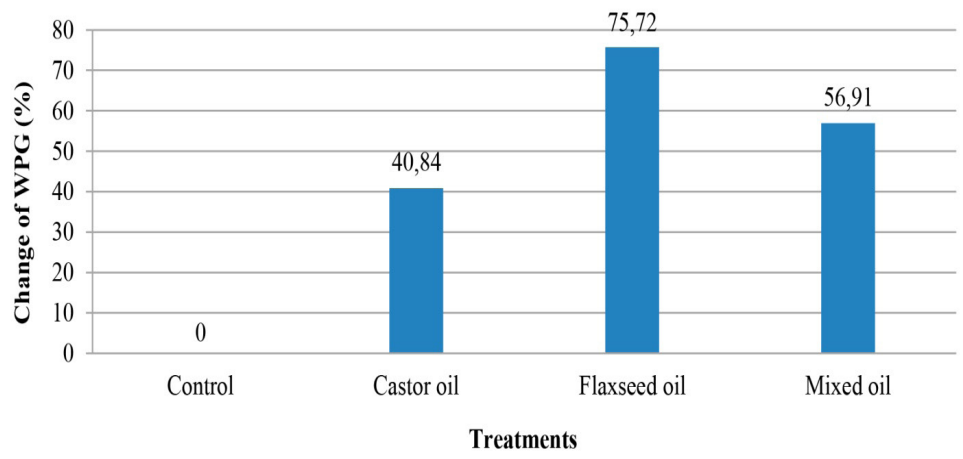

Figure 2: WPG in the treated wood compared to weights prior to hot-cold oil treatment. 
Several studies have reported that the WPG values after oil heat treatment were $84 \%-86 \%$ for aspen wood (Bazyar 2012), $42 \%$ - $51 \%$ for pine wood, and $10 \%$ - $18 \%$ for spruce wood (Sailer and Rapp 2001). Spear et al. 2006 also reported that pine wood treated with flaxseed oil at two different oil heat treatments yielded a WPG value of $87 \%$ and $90 \%$. In the hot-cold oil treatment, the cooling process may contract the air inside the wood that had expanded during the heating process and, this contraction of the air can produce a vacuum effect that enables better penetration of the oil into the wood (Awoyemi et al. 2009). In this study, during the hot-cold oil treatment, no additional pressure or vacuum was applied in order to increase the WPG value. Nevertheless, the WPG increment may also due to the density and viscosity values of the treatment oils. These types of different properties of oils may able to increase oil penetration by making an improvement effect oil absorption during the hot-cold oil treatment. The increased oil penetration can also increase the WPG value. Awoyemi et al. 2009 reported that oil heat treatment caused a WPG increase in the wood. All these evaluations and observations demonstrate that the WPG values in Table 3 are consistent with the results of previous studies.

\section{Density}

Table 4 gives the results of density measurements for the hot-cold oil-treated wood samples. Figure 3 displays the density change percentages of all samples. The change percentage was calculated according to the oven-dry weight.

Table 4: Density results of the control and treated Brutia pine sapwood samples.

\begin{tabular}{|c|c|}
\hline Treatments & Mean $\left(\mathrm{g} / \mathrm{cm}^{3}\right)^{*}$ \\
\hline Control & $0,50 \pm 0,03 \mathrm{~d}$ \\
\hline Castor oil & $0,74 \pm 0,04 \mathrm{e}$ \\
\hline Flaxseed oil & $0,92 \pm 0,07 \mathrm{f}$ \\
\hline Mixed oil & $0,83 \pm 0,05 \mathrm{~g}$ \\
\hline
\end{tabular}

*The difference between the values indicated by different letters within the same column is significant $(p \leq 0,05 ; 95 \%)$.

The hot-cold oil treatment significantly increased the density of Brutia pine sapwood compared with the untreated control wood. The highest density increase was $85 \%$ in the flaxseed oil treatment, while the lowest was $48 \%$ in the castor oil treatment. This result revealed that the effect of the hot-cold oil treatment on the oil absorption amount of Brutia pinewood showed to be there is a significant difference among treatment oils and, the flaxseed oil treatment significantly increased the quantity of oil absorbed by the pine wood compared to the other oil treatments. This can imply that the natural properties such as the density and viscosity of the treatment oils affected the oil quantity absorbed by the wood. These results in line with studies by some researchers (Falemara et al. 2015, Owoyemi and Kayode 2007) agree with his findings that the absorption or weight gain is different according to oil type. This increase in density was due to the fact that the flaxseed oil treatment had a greater oil uptake per unit volume compared to the other oil treatments. The degree of density increment may depend on the density and viscosity values of the oils used during the hot-cold oil treatment. As a natural result of the different density and viscosity of flaxseed oil, the volumetric increment resulting from the oil amount taken in per unit volume can give the wood high-density values. This density improvement may also be related to the mass increment in the wood. Therefore, the mass increment in wood subjected to the hot-cold oil treatment can also affect the wood's density and void volume, i.e., the empty spaces within the wood.

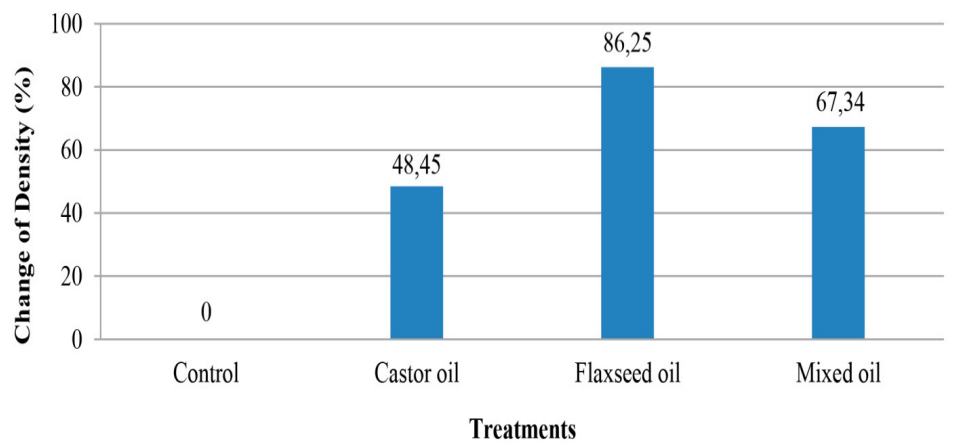

Figure 3: Density changes in the treated wood compared to the untreated control 
Bozkurt et al. (1993) reported that the wood preservatives absorbed by wood material reduced the void (air) volume within the wood, and the reduction in the void volume of the wood indirectly supported the weight gain due to oil uptake. In this study, we observed (Table 1) that the oils increased the density of Brutia pine sapwood after the hot-cold oil treatment. The increasing density may cause mass increases by displacing air with oil during the treatment process. The factor affecting this situation is the heating of the air in the wood cell voids with the application of hot oil initially in wood impregnation. It is thought that this expansion may be caused by the oil settling in the wood cavities as a result of the rapid contraction of the air in the cell spaces by the cold oil treatment (Ahmed et al. 2017).

\section{Water absorption}

Table 5 presents the results of the water absorption (WA) testing of the hot-cold oil-treated wood samples. The WA change rates of all samples are shown in Figure 4. The change rates were calculated according to those of the control.

Table 5: WA results of the control and treated Brutia pine sapwood samples.

\begin{tabular}{|c|c|}
\hline Treatments & Mean (\%)* \\
\hline Control & $64,41 \pm 2,3 \mathrm{~h}$ \\
\hline Castor oil & $29,78 \pm 2,8 \mathrm{i}$ \\
\hline Flaxseed oil & $19,07 \pm 3,3 \mathrm{j}$ \\
\hline Mixed oil & $24,28 \pm 1,0 \mathrm{k}$ \\
\hline
\end{tabular}

*The difference between the values indicated by different letters within the same column is significant $(p \leq 0,05 ; 95 \%)$.

The results presented in Table 5 show that the WA values ranged from $19,07 \%$ to $29,78 \%$ when the hotcold oil treatment was applied to the wood specimens. A decrease of 53,76\% - 70,39\% was achieved in the treated samples compared to the untreated control samples. Moreover, these results revealed that the lowest WA value was $19,07 \%$ when the hot-cold oil treatment was applied with flaxseed oil, and hence, the WA decrease was the highest ( 70,39\%). In addition, the ANOVA showed that the applied hot-cold oil treatment had a significant effect on the WA properties of the wood samples. Several different studies have reported that hygroscopicity and water absorption decreased in oil heat-treated-wood material (Hyvonen et al. 2005, Hofland and Tjeerdsma 2005). Other studies have also stated that the molecule size of some dry oils, such as flaxseed oil, is too large to penetrate the cell walls. However, they said that such oils remain mostly in the cell lumens, and penetrate into the wood to form a water-repellent outer layer in the wood (Olsson et al. 2001, Hill 2006, Wang 2007). Table 5 shows that the lower WA values were measured in the hot-cold oil-treated Brutia pine sapwood compared to the non-treated control wood. This means that the hot-cold oil treatment reduces water intake and improves water repellent effectiveness. We can say that these results are similar to the literature findings.

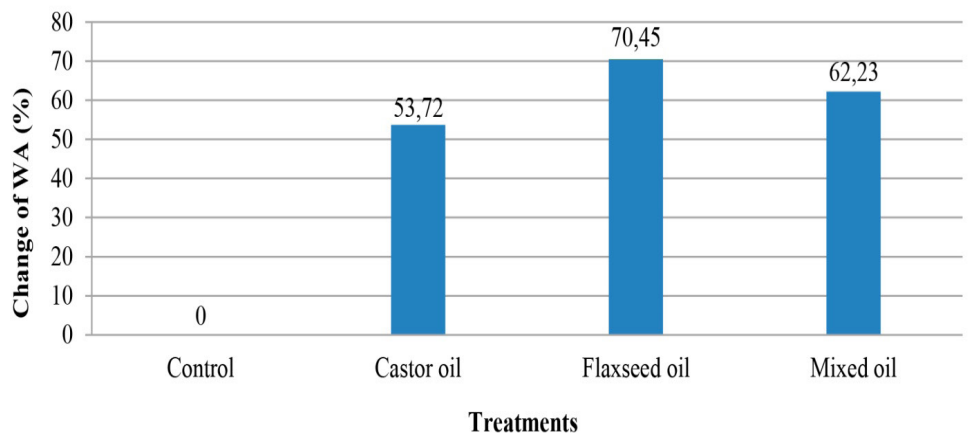

Figure 4: WA change of the treated wood compared to the untreated control.

\section{Volumetric shrinking}

Table 6 presents the results of the volumetric shrinking (VSH) testing for the wood samples with and without the hot-cold oil treatment. The VSH change rates of all samples are presented in Figure 5. The change rates were calculated according to the control samples. 
Table 6: VSH results of the control and treated Brutia pine sapwood samples.

\begin{tabular}{|c|c|}
\hline Treatments & Mean (\%)* \\
\hline Control & $9,52 \pm 0,3 \mathrm{n}$ \\
\hline Castor oil & $7,66 \pm 0,4 \mathrm{o}$ \\
\hline Flaxseed oil & $5,08 \pm 0,3 \mathrm{p}$ \\
\hline Mixed oil & $6,83 \pm 0,4 \mathrm{q}$ \\
\hline
\end{tabular}

* The difference between the values indicated by different letters within the same column is significant $(p \leq 0,05 ; 95 \%)$.

The ANOVA results of Table 6 demonstrate that the hot-cold oil treatment had a significant effect on the VSH properties of the wood specimens. The VSH percentages of the treated samples were significantly reduced compared with those of the untreated-samples. For example, the VSH values of the hot-cold oil-treated samples measured between 5,8\% and 7,66 \%. Therefore, a VHS reduction of $19,54 \%$ to $46,64 \%$ was achieved, i.e., the treated wood samples had become more dimensionally stable. Flaxseed oil in the hot-cold oil process had the highest WPG (75,72\%) (Figure 2) and the lowest VSH (5,08 \%) (Table 6), the highest change or decrease $(46,65 \%)$ was found (Figure 5$)$, and the highest dimensional stability was achieved. In contrast, when the castor oil was utilized in the hot-cold oil treatment, the highest VSH (7,66 \%) was obtained, and the lowest change rate $(19,40 \%)$ (Figure 5$)$ and the lowest dimensional stability were reached. These results can be explained by the decreased hemicellulose and the reduction of the volumetric shrinking by the wood hydroxyl groups during the hot-cold oil process, especially in the hot oil phase. These results can be explained by the fact that samples were not exposed to moisture long enough to reach equilibrium and, treatments that had higher oil uptake had lower shrinkage because of slower moisture adsorption. In other words, these results can also be explained as follows. The samples with slower moisture uptake after hot-cold linseed oil treatment may have yielded less VSH values. Therefore, the use of flaxseed oil in the hot-cold treatment technique may be a factor in improving dimensional stability. Falemara et al. (2015) stated that the high oil uptake reduces exposure to moisture for a long time and this reduces the volumetric shrinking of the wood and improves its dimensional stability. Some researchers have found that the dimensions of heat-treated wood material were more stable compared to those of untreated material (Stamm et al. 1946), and that its volumetric shrinking decreased and dimensional stability improved (Syrjanen 2001). Others also reported that the oil heat treatment reduced the VSH of the wood material (Sailer and Rapp 2001, Salim et al. 2010).

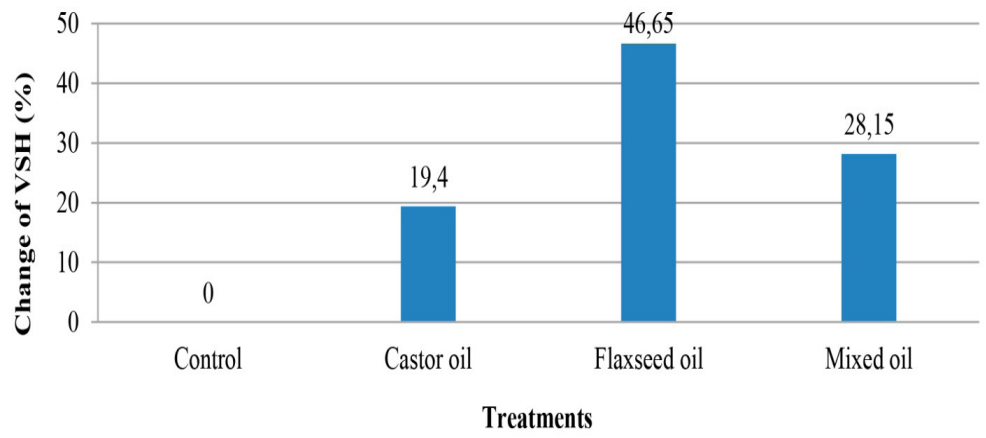

Figure 5: VSH changes of the treated wood compared to the untreated control.

According to Tomak and Yildiz (2012), the vegetable-based oils can create a hydrophobic layer that reduces water uptake and a mechanical barrier effect within the wood structure, but they may not provide alone a full protective effect against biotic harmful such as fungi and termites; in this case, they can be used in the wood treatment process together with various biocides like pesticides and fungicides. In this sense, Ozgenc et al. (2013) reported that the vegetable oils can be used with new generation wood preservatives such as Celcure AC 500 (Alkali Copper Quaternary) and MCQ (Micronized Copper Quaternary), and micro-emulsions that reduce oil retention and contain different biocides. 


\section{CONCLUSIONS}

This study has shown that the hot-cold oil treating method results in high oil uptake; this can be a major disadvantage for the treatment; because the economic cost for such wood modification operations will depend on the cost of the treatment oils.

When the hot-cold oil treatment was applied with only castor oil, it did not increase the decay resistance for either fungus. In addition, these results measured in the small sapwood samples showed that the hot-cold treatment with castor oil had a significant effect on the physical properties. The hot-cold flaxseed oil treatment had a significant impact statistically not only on the physical properties of the wood but also on its decay resistance against both fungi types.

The hot-cold oil treatment technique with vegetable oils can significantly improve the physical properties of Brutia pine sapwood, including the WPG, WA, density, and VSH. In particular, the hot-cold flaxseed oil treatment can increase the decay resistance of Brutia pine sapwood against wood-decay fungi. Although these oils increase the decay resistance, they are not able to sufficient to prevent decay by themselves. In addition, investigations should be carried out by other studies to determine whether this biological resistance improvement of Brutia pine sapwood is sufficient to warrant its use in contact with soil.

The wood modification based on hot-cold oil treatment can be improved together with oil-based new generation wood preservatives and micro-emulsions. Such applications can increase the wood preservation effectiveness of vegetable oils. But, for full protective efficacy, high oil absorption or retention may be required. As the oil absorption increases, it can bleed from the wood. This can make the treatment process non-economical.

\section{ACKNOWLEDGMENTS}

The authors are grateful for the support from the TR TUBITAK-Directorate of Science Fellowships and Grant Programs (BIDEB) (Grant No. 2209-A: 1919B011601622).

\section{REFERENCES}

Acar, K. 2019. Acar Chemicals Inc. https://www.acarchemicals.com/sayfalar.asp?Language$\mathrm{ID}=1 \& \mathrm{cid}=3 \& \mathrm{id}=8 \& \mathrm{id} 2=8718$

Ahmed, S.A.; Morén, T.; Sehlstedt-Persson, M.; Blom, Å. 2017. Effect of oil impregnation on water repellency, dimensional stability and mold susceptibility of thermally modified European aspen and downy birch wood. J Wood Sci 63(1): 74-82. https://doi.org/10.1007/s10086-016-1595-y

ASTM. 2007. Standard test method for wood preservatives by laboratory soil-block cultures. ASTM D1413-07E1. 2007. ASTM: West Conshohocken, PA, USA. https://www.techstreet.com/standards/astmd1413-07e1?product_id=1562947

Awoyemi, L.; Cooper, P.A.; Ung, T.Y. 2009. In-treatment cooling during thermal modification of wood in soy oil medium: Soy oil uptake, wettability, water uptake and swelling properties. European Journal of Wood and Wood Products 67: 465-470. https://doi.org/10.1007/s00107-009-0346-9

Bak, M.; Németh, R. 2012. Changes in swelling properties and moisture uptake rate of oil-heat-treated poplar (Populus euramericana CV. Pannónia) wood. BioResources 7(4): 5128-5137. http://publicatio.nyme. hu/1070/1/BioRes_07_4_5128_Bak_Nemeth_Changes_Swelling_Moisture_OilHeat_Poplar_2781.pdf

Bazyar, B. 2012. Decay resistance and physical properties of oil heat treated aspen wood. BioResources 7(1): 696-705. https://ojs.cnr.ncsu.edu/index.php/BioRes/article/view/BioRes_07_1_0696_Bazyar_Decay_ Resistance_Properites_Oil_Heat_Treated_Aspen

Bozkurt, A.Y.; Goker, Y.; Erdin, N. 1993. Wood Impregnation Technique. 3779/425. Istanbul University. Faculty of Forestry Publications: Istanbul, Turkey

TS EN. 1996. Wood preservatives - Determination of the toxic values against wood destroying basidiomycetes cultured on an agar medium. TS EN 5563. 1996. Turkish Standard Institution: Ankara, Turkey. 
Falemara, B.C.; Ampitan, T.; Oyeleye, I.O. 2015. Effects of Hot and Cold Treatment Techniques on Preservative Absorption of Triplochiton Scleroxylon (Obeche) Against Fungi Attack. Appl Trop Agric J 20(1): 146-151.

Hill, C.A.S. 2006. Wood modification: Chemical, thermal and other processes. Wiley: Chichester. UK. Part 3.

Hofland, A.; Tjeerdsma, B.F. 2005. Wood protection by chemical modification. ECOTAN $3^{\text {rd }}$ Report,

Hyvonen, A.; Piltonen, P.; Nelo, M.; Niinimaki, J. 2005. Wood protection of tomorrow - Potential of modified crude tall oil formulations in wood protection. In Proceedings of the Seventh Finnish Conference of Environmental Sciences, May12-13, Jyvaskyla. Finnish Society for Environmental Sciences. University of Jyvaskyla: 35-38.

ISO. 2014. Physical and mechanical properties of wood - Test methods for small clear wood specimens Part 1: Determination of moisture content for physical and mechanical tests. ISO 13061-1. 2014. International Organization for Standardization: Geneva, Switzerland.

ISO. 2014. Physical and mechanical properties of wood - Test methods for small clear wood specimens - Part 2: Determination of density for physical and mechanical tests. ISO 13061-2. 2014. International Organization for Standardization: Geneva, Switzerland.

ISO. 1982. Wood - Sampling sample trees and logs for determination of physical and mechanical properties of wood in homogeneous stands. ISO 4471. 1982. International Organization for Standardization: Geneva, Switzerland.

ISO. 1982. Wood-Determination of volumetric shrinkage. ISO 4858. 1982. International Organization for Standardization: Geneva, Switzerland.

Kolsarici, Ö.; Kaya, K.D.; Göksoy, A.T.; Arıŏlu, H.; Kulan, E.G.; Day, S. 2015. New Searches in Oilseed Production. Agricultural Engineering VIII. In Technical Congress Proceedings Book-1, Ankara, Turkey: 401-425 (in Turkish).

Lee, S.H.; Zaidon, A.; Lum, W.C.; Halip, J.A.; Ang, A.F.; Tan, L.P.; Chin, K.L.; Tahir, M.P. 2018. Thermal treatment of wood using vegetable oils: A review. Constr Build Mater 181: 408-419. https://doi.org/10.1016/j.conbuildmat.2018.06.058

Lyon, F.; Thevenon, M.F.; Hwang, W.J.; Imamura, Y.; Gril, J.; Pizzi, A. 2007. Effect of an oil heat treatment on the leachability and biological resistance of boric acid impregnated wood. Ann For Sci 64(6): 673-678. https://doi.org/10.1051/forest:2007046

Németh, R.; Bak, M.; Tolvaj, L.; Molnár, S. 2009. The effect of thermal treatment using vegetable oils on physical and mechanical properties of poplar and robinia wood. Proligno 5(2): 33-37. https://www.proligno.ro/en/articles/2009/2/paper2.htm

Nicholas, D.D. 1973. Wood deterioration and its prevention by preservative treatment: Volume I. Degradation and protection of wood. Syracuse University Press: Syracuse, New York, USA.

Nuoponen, M. 2005. FT-IR and UV Raman spectroscopic studies on thermal modification of Scots pine wood and its extractible compounds. Academic Dissertation. University of Technology: Helsinki. 40p.

Olsson, T.; Megnis, M.; Varna, J.; Lindberg, H. 2001. Measurement of the uptake of linseed oil in pine by the use of an X-ray micro densitometry technique. J Wood Sci 47(4): 275-281. https://doi.org/10.1007/ BF00766713

Onat, B.; Arığllu, H.; Güllüoğlu, L.; Kurt, C.; Bakal, H. 2017. Oil seeds and crude oil production in the world and in Turkey. KSU J Nat Sci 20 (Special Issue): 149-153.

Owoyemi, J.M.; Kayode, J.O. 2007. The effects chromated copper arsenate and solignum oil on the resistance of Gmelina arborea (Roxb) to termites' attack. Nigeria J For 37(1): 30-37.

Ozgenc, O.; Yildiz, U.C.; Yildiz, S. 2013. The wood surface protection with some new generation wood 
preservatives and coating processings against weathering conditions. Artvin Coruh University Journal of Forestry Faculty 14(2): 203-215. http://edergi.artvin.edu.tr

Rapp, A.O.; Sailer, M. 2000. Heat treatment of wood in Germany-State of the art. In Proceedings of the seminar on production of heat treated wood in Europe. Helsinki, 20 November 2000. http://www.thermallytreatedwood.com/Library/Technology/Germany.pdf

Rowell, R.M.; Banks, W.B. 1985. Water repellency and dimensional stability of wood. Gen. Tech. Rep. FPL-50. Department of Agriculture, Forest Service, Forest Products: Madison, WI: U.S. https://www.fs.usda. gov/treesearch/pubs/8912

Sailer, M.; Rapp, A.O. 2001. Use of vegetable oils for wood protection. In COST Action E22: Environmental optimisation of wood protection. Einbek, Germany, 8-10 November 2001.

Salim, R.; Ashaari, Z.; Samsi, H.W. 2010. Effects of oil heat treatment on physical properties of Semantan bamboo (Gigantochloa scortechinii Gamble). Mod Appl Sci 4(2): 107-113. https://citeseerx.ist.psu.edu/ viewdoc/download?doi=10.1.1.654.5853\&rep=rep1\&type=pdf

Scholz, V; Silva, J.N. 2008. Prospects and risks of the use of castor oil as a fuel. Biomass Bioenerg 32: 95-100. https://doi.org/10.1016/j.biombioe.2007.08.004

Schneider, M.H. 1980. Hygroscopicity of wood impregnated with linseed oil. Wood Sci Technol 14: 107114. https://doi.org/10.1007/BF00584040

Spear, M.J.; Hill, C.A.S.; Curling, S.F.; Jones, D.; Hale, M.D. 2006. Assessment of the envelope effect of three hot oil treatments: Resistance to decay by Coniophora puteana and Postia placenta. IRG/WP 0640344. The International Research Group on Wood Preservation

Stamm, A.; Burr, H.; Kline, A. 1946. Stayb-wood-A heat stabilized wood. Ind Eng Chem 38(6): 630-634. https://doi.org/10.1021/ie50438a027

Syrjanen, T. 2001. Production and classification of heat treated wood in Finland. In Proceedings of Special Seminar COST ACTION E22, Environmental Optimisation of Wood Protection. Antibes, France.

Tasdelen, M.; Can, A.; Sivrikaya, H. 2019. Some physical and mechanical properties of maritime pine and poplar exposed to oil-heat treatment. Turk J For 20(3): 254-260.https://doi.org/10.18182/tjf.566647

Tjeerdsma, B.F.; Stevens, M.; Mılıtz, H.; Van Acker, J. 2002. Effect of process conditions on moisture content and decay resistance of hydro-thermally treated wood. Holzforschung 54(5): 94-99. http://hdl.handle.net/1854/LU-157271

Tomak, E.D.; Yildiz, U.C. 2012. Applicability of vegetable oils as a wood preservative. Artvin Coruh University Journal of Forestry Faculty 13(1):142-157. http://edergi.artvin.edu.tr

TS .2012. Testing methods for the effects of wood impregnating substances. TS 345.2012. Turkish Standard Institution: Ankara, Turkey.

Welzbacher, C.R.; Rapp, A.O. 2002. Comparison of thermally treated wood originating from four industrial scale processes - durability. IRG/WP 02 40229. International Research Group on Wood Preservation.

Wang, J. 2007. Initiating evaluation on thermal-oil treatment for post-MPB lodgepole pine. Forintek Canada Corp.: Vancouver, BC, Canada.

Wang, J.; Cooper, P. 2005. Effect of oil type, temperature and time on moisture properties of hot oil-treated wood. Holz Roh- Werkst 63: 417-422. https://doi.org/10.1007/s00107-005-0033-4 